\title{
Avaliação dos Testes Experimentais com Diesel de Cana (AMD 10) EM Frota de Ônibus Urbanos na Cidade de São Paulo
}

\author{
Lian S. Izquierdo ${ }^{1}$, Gian G. Marques ${ }^{1}$ and Pedro Rama $a^{1.2}$ \\ ${ }^{1}$ MAN Latin America \\ ${ }^{1.2}$ SPTrans \\ E-mails: lian.izquierdo@volkswagen.com.br, gian.marques@volkswagen.com.br, \\ pedro.rama@sptrans.com.br
}

\section{RESUMO}

A exemplo da produção de etanol, o diesel de cana é produzido a partir de fermentação. Modernos métodos de biotecnologia usam leveduras modificadas geneticamente para conduzir o processo de fermentação, convertendo um concentrado rico em açúcar em diesel de cana por meio de sístense biológica. A MAN Latin América vem pesquisando e realizando testes com diferentes combustíveis renováveis para fins automotivos.

Este trabalho apresenta e avalia os resultados dos testes experimentais realizados em três ônibus urbanos originais que utilizaram exclusivamente a mistura de diesel de cana AMD 10 (10\% diesel de cana e 90\% óleo diesel S50/B5), em condições reais de operação. Estes ônibus foram comparados com a média da frota movida a óleo diesel S50/B5, com relação ao seu desempenho operacional e durabilidade do sistema de injeção e alimentação de combustível, além do período de troca de filtros de combustível.

\section{INTRODUÇÃO}

A cidade de São Paulo é a maior da América do Sul possuindo 11 milhões de habitantes distribuídos em uma área de $1.523 \mathrm{~km}^{2}$. A Região Metropolitana de São Paulo (RMSP) se extende por mais de 8 mil km $\mathrm{km}^{2}$ e tem cerca de 20 milhões de habitantes [1]. Isto a coloca entre as dez maiores regiões metropolitanas do mundo impondo-lhe desafios de mesma magnitude nas áreas de transporte, resíduos sólidos, abastecimento de água e energia.

Em 2005, foi realizado o primeiro Inventário de Emissões de Gases de Efeito Estufa (GEE) do município de São Paulo que apontou o uso de energia e a gestão de resíduos sólidos como as maiores fontes de emissões de GEEs na cidade. No caso da energia, $90 \%$ são originárias das emissões veiculares. As emissões geradas pelos resíduos sólidos já foram reduzidas pelo funcionamento das duas usinas de biogás no aterro sanitário dos Bandeirantes. A Lei $\mathrm{n}^{\circ}$ 14.933/09, conhecida como a Lei da Mudança Climática, apresenta as metas e estratégias para redução das emissões de GEE no município de São Paulo.

Page 1 of 16 
Seu desdobramento na área de transportes inclui a priorização dos coletivos, estímulo ao uso de meios de transporte com menor potencial poluidor, priorização do uso dos trólebus, metrô, trem e outros meios de transporte utilizadores de energia renovável, o monitoramento e armazenamento de cargas privilegiando o horário noturno, a implantação de corredores de ônibus, programas e incentivos para carona solidária e transporte compartilhado e a continuidade do Programa de Inspeção Ambiental Veicular.

Outro ponto fundamental é que programas, contratos e autorizações municipais de transportes públicos devem considerar redução progressiva do uso de combustíveis fósseis, adotando meta progressiva de redução de pelo menos $10 \%$ a cada ano, já a partir de 2008 e a utilização, em 2017, de combustível renovável não-fóssil por todos os ônibus do sistema de transporte público do município [2].

Atualmente a frota de ônibus é composta de 15.063 unidades com idade média de 4,3 anos [2]. O consumo de óleo diesel chega a 390 milhões de litros por ano [2]. Até 2011, mais de 1.300 ônibus já operavam com algum combustível alternativo [1]. Além disto, novas tecnologias de propulsão, como veículos híbridos e elétricos, já estavam sendo estudadas para testes.

Desta forma, a MAN Latin América vem trabalhando em cooperação com o órgão gestor de transporte da cidade de São Paulo suportando a realização de testes experimentais em ônibus urbanos a fim de avaliar, tecnicamente, o impacto do uso de diferentes combustíveis renováveis em seus motores e veículos originais.

\section{OBJETIVO}

O principal objetivo deste programa de testes foi avaliar o desempenho em campo e durabilidade de ônibus urbanos com uso da mistura de diesel de cana AMD 10. Este estudo pretende avaliar o desempenho operacional e a durabilidade dos sistemas de injeção e alimentação de combustível, além do período de troca dos filtros de combustível. Testes de emissões não fizeram parte do escopo deste projeto.

\section{MATERIAIS \& MÉTODOS}

\subsection{Combustível}

O uso de diesel de cana AMD 10 aparece como uma oportunidade para uso em veículos originais por atender às especificações estabelecidas pela Resolução ANP n ${ }^{\circ}$ 42/2009, que define as propriedades físico-químicas do óleo diesel S50/B5, comercializado no Brasil.

Todo diesel de cana AMD 10 utilizado nos testes para abastecimento dos ônibus urbanos foi disponibilizado pela BR Distribuidora na sede da Viação Santa Brígida, em São Paulo/SP. A tabela 1 apresenta um comparativo entre as principais propriedades físicoquímicas do diesel de cana puro e do óleo diesel S50/B5. 
Tabela 1: Comparativo das propriedades físico-químicas [3]

\begin{tabular}{|l|c|c|c|c|}
\hline \multicolumn{1}{|c|}{ Propriedade } & Un. & $\begin{array}{c}\text { Método } \\
\text { ASTM }\end{array}$ & Diesel de Cana & Diesel S50/B5 \\
\hline Carbono & $\%$ & D5291 & 84,71 & 85,54 \\
\hline Hydrogênio & $\%$ & D5291 & 15,31 & 14,46 \\
\hline Número Cetano & - & D613 & 58,0 & 52,2 \\
\hline Densidade & $\mathrm{Kg} / \mathrm{m}^{3}$ & D4052 & 768,7 & 842,6 \\
\hline $\begin{array}{l}\text { Viscosidade } \\
\text { Cinemática } 40{ }^{\circ} \mathrm{C}\end{array}$ & $\mathrm{cst}$ & $\mathrm{D} 445$ & 2,30 & 2,73 \\
\hline $\begin{array}{l}\text { Poder Calorífico } \\
\text { Superior (PCS) }\end{array}$ & $\mathrm{MJ} \mathrm{kg}^{-1}$ & $\mathrm{D} 240$ & 46,9 & 45,3 \\
\hline
\end{tabular}

2.2 Ônibus Urbanos

O projeto abrangeu três ônibus urbanos com motor traseiro, VW 17.260 OT, originais de fábrica, com 12 metros de comprimento e peso bruto total de 18t, e motor MWM International em conformidade com limites de emissões estabelecidos pelo Proconve P5 (Euro III). Estes veículos foram equipados com caixa ZF automatizada, de 6 marchas, a fim de se garantir maior conforto aos motoristas e melhor troca de marchas. A figura 1 mostra uma foto dos ônibus estacionados na garagem da Viação Santa Brígida.

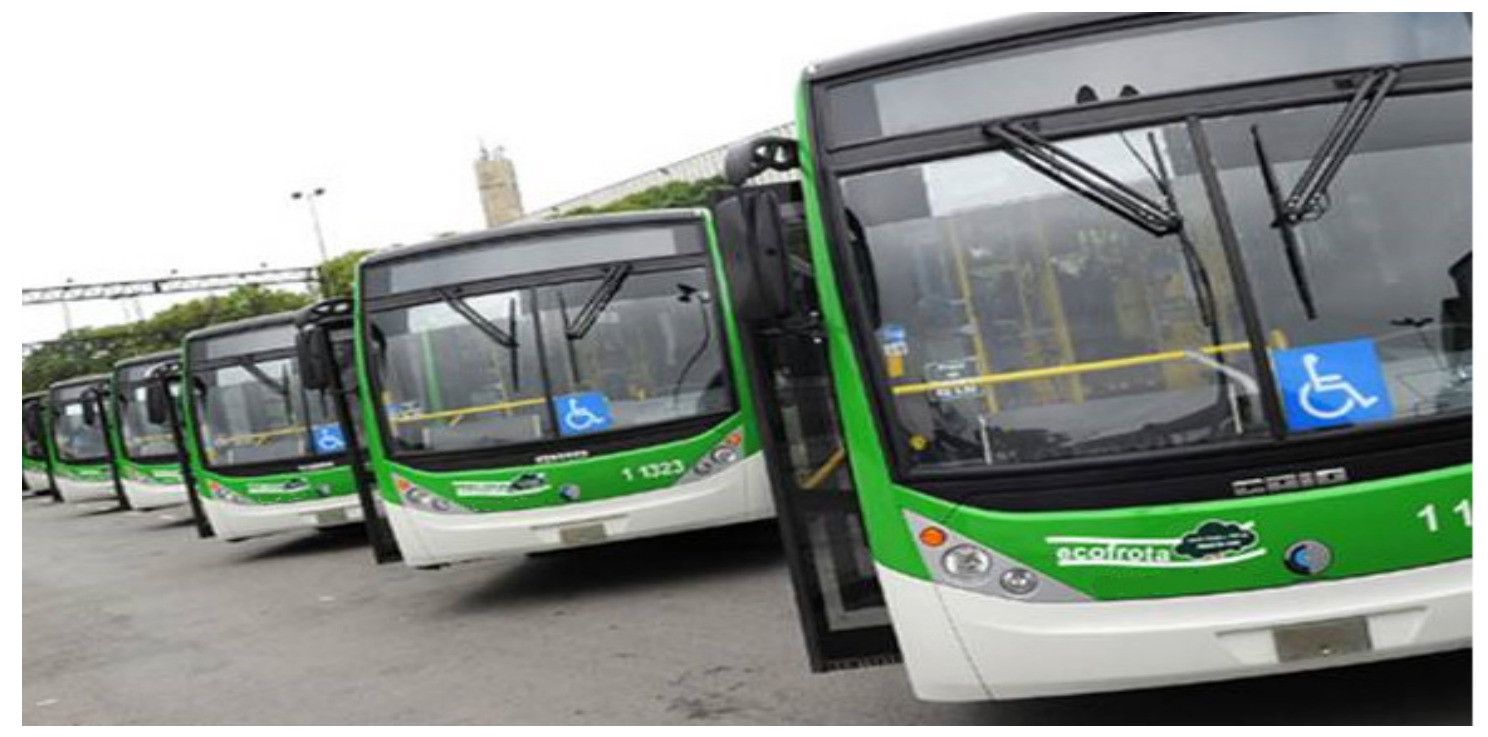

Figura 1: Vista dos ônibus urbanos VW 17.260 OT

A tabela 2 fornece maiores informações sobre o motor MWM Acteon 6.12 TCE utilizado nestes testes. 
Tabela 2: Características dos motores

\begin{tabular}{|l|l|}
\hline Modelo do Motor & MWM 6.12 Acteon TCE \\
\hline Ciclo de Operação & Diesel, 4 tempos \\
\hline Cilindros / Deslocamento & 4 em linha / 7,2 litros \\
\hline Potência Máxima & $191 \mathrm{~kW}(260 \mathrm{HP}) / 2500 \mathrm{rpm}$ \\
\hline Torque Torque & $900 \mathrm{Nm} / 1300-1900 \mathrm{rpm}$ \\
\hline Sistema de Injeção & Common Rail \\
\hline Padrão de Emissões & Proconve P5 (Euro III) \\
\hline
\end{tabular}

2.3 Metodologia dos Testes

O escopo dos testes compreendeu a utilização de ônibus com motor traseiro em rotas urbanas na cidade de São Paulo, operando totalmente ou parcialmente carregado, ou até mesmo vazio, dependendo da demanda de passageiros. A rota utilizada pelos cinco ônibus foi da linha 8100 (Terminal Pirituba - Terminal Lapa).

O desempenho operacional dos ônibus foi avaliado por meio do consumo de combustível $(\mathrm{km} / \mathrm{l})$ e o número de ocorrência de falhas em campo a partir da coleta de dados diários de distâncias percorridas e abastecimentos. Os resultados discrepantes, eventualmente causados por mudanças de rota, foram descartados, de modo a manter a consistência das informações.

Para avaliação dos componentes os ônibus tiveram os tanques originais, roteiros e filtros de combustíveis e dos conjuntos de injeção: bomba, bicos injetores e tubulação de alta pressão substituídos por novos protocolados. Ao final dos testes uma análise da vida útil dos componentes foi realizada. Uma análise boroscópica nos motores foi realizada antes e após os testes.

Durante todo o período de execução dos testes, as revisões periódicas foram realizadas na concessionária VW Tietê, de acordo com o plano de manutenação original dos veículos. O período de rodagem entre revisões foi de aproximadamente $30.000 \mathrm{~km}$ e qualquer atividade corretiva realizada nos ônibus foi reportada.

Os resultados foram reportados com base na comparação direta entre os três ônibus urbanos operados exclusivamente com diesel de cana AMD 10, com a média da frota movida a óleo diesel S50/B5. A tabela 3 apresenta as datas de inspeção, atualização e a quilometragem rodada pelos veículos que operaram com AMD 10 durante todo período de teste. 
Tabela 3: Datas de inspeção, atualização e quilometragem dos veículos testados

\begin{tabular}{|l|c|c|c|}
\hline Placa & ELQ-5822 & ELQ-5819 & ELQ-5807 \\
\hline $\mathrm{N}^{\text {o }}$ frota & $\mathbf{3 1 8}$ & $\mathbf{3 1 7}$ & $\mathbf{3 1 6}$ \\
\hline Data da atualização & $09 / 12 / 11$ & $08 / 12 / 11$ & $07 / 12 / 11$ \\
\hline Km inicial & 33.569 & 28.813 & 31.071 \\
\hline Data da $1^{\text {a }}$ revisão & $07 / 05 / 12$ & $08 / 05 / 12$ & $09 / 05 / 12$ \\
\hline Km após $1^{\text {a }}$ revisão & 64.355 & 59.790 & 58.912 \\
\hline Data da 2 ${ }^{\text {a revisão }}$ & $30 / 08 / 12$ & $29 / 08 / 12$ & $28 / 08 / 12$ \\
\hline Km após 2 ${ }^{\text {a }}$ revisão & 93.728 & 87.593 & 85.846 \\
\hline Data da Atualização & $07 / 02 / 2013$ & $08 / 02 / 2013$ & $09 / 02 / 2013$ \\
\hline Km Final & 119.557 & 118.614 & 115.402 \\
\hline Km rodados & 85.988 & 89.801 & 84.331 \\
\hline
\end{tabular}

\section{RESULTADOS \& DISCUSSÕES}

\subsection{Boroscopia dos motores}

A análise boroscópica é um processo de inspeção que permite a captação e reprodução de imagens no interior da câmara de combustão. Esta tecnologia possibilita a inspeção sem a necessidade de desmontagem do motor, reduzindo assim tempo e custo.

Foram verificadas as camisas, pistões e válvulas de cada um dos três motores testados com AMD 10 a fim de se avaliar as condições físicas destes componentes após um ano de teste. $\mathrm{O}$ aspecto visual dos componentes condiz com a solicitação do teste e não mostrou falhas ou desgastes anormais relacionados ao uso do AMD 10. No anexo A e B, é mostrado um comparativo de algumas imagens captadas durante a boroscopia, referentes aos motores dos veículos 317 e 318, antes e depois do período de execução dos testes.

\subsection{Sistema de Injeção de Combustível}

O sistema de injeção common rail trabalha com altas pressões de injeção, curvas de injeção exatas e dosagem extremamente precisa do volume do combustível. Portanto, é necessário avaliar a qualidade da injeção com o uso de AMD 10 realizando a protocolação inicial dos sistemas. Desta forma, antes do iníco do teste é medida a curva de injeção de todos os injetores, e no final foi repetida esta medição, para verificar possiveis desvios com relação a primeira medição. 
A avaliação funcional dos injetores após o teste de rodagem, mostraram resultado neutro e dentro do esperado. Somente o injetor 1449 do ônibus 317 mostrou curva de débito injetado abaixo do estado de fornecimento, a 250 bar de pressão, porém não é esperada influência funcional sobre o motor. $\mathrm{O}$ injetor apresentou curvas normais nos pontos de medição restantes. $\mathrm{O}$ funcionamento irregular neste ponto está provavelmente ligado a leve formação de depósitos. A figura 2 e 3 mostram com detalhes esta diferença.

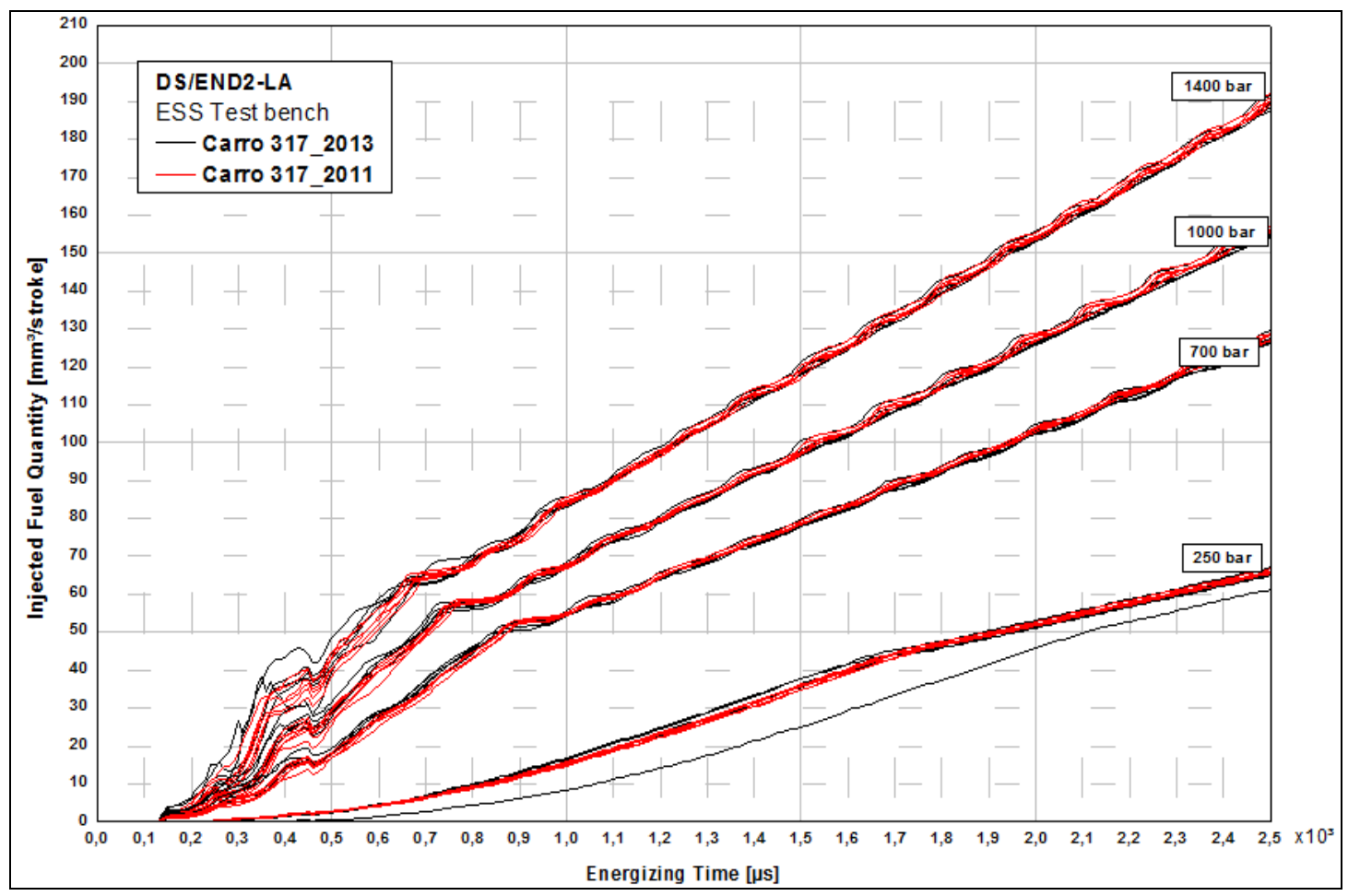

Figura 2: Comparativo débito antes e depois - veículo 317 


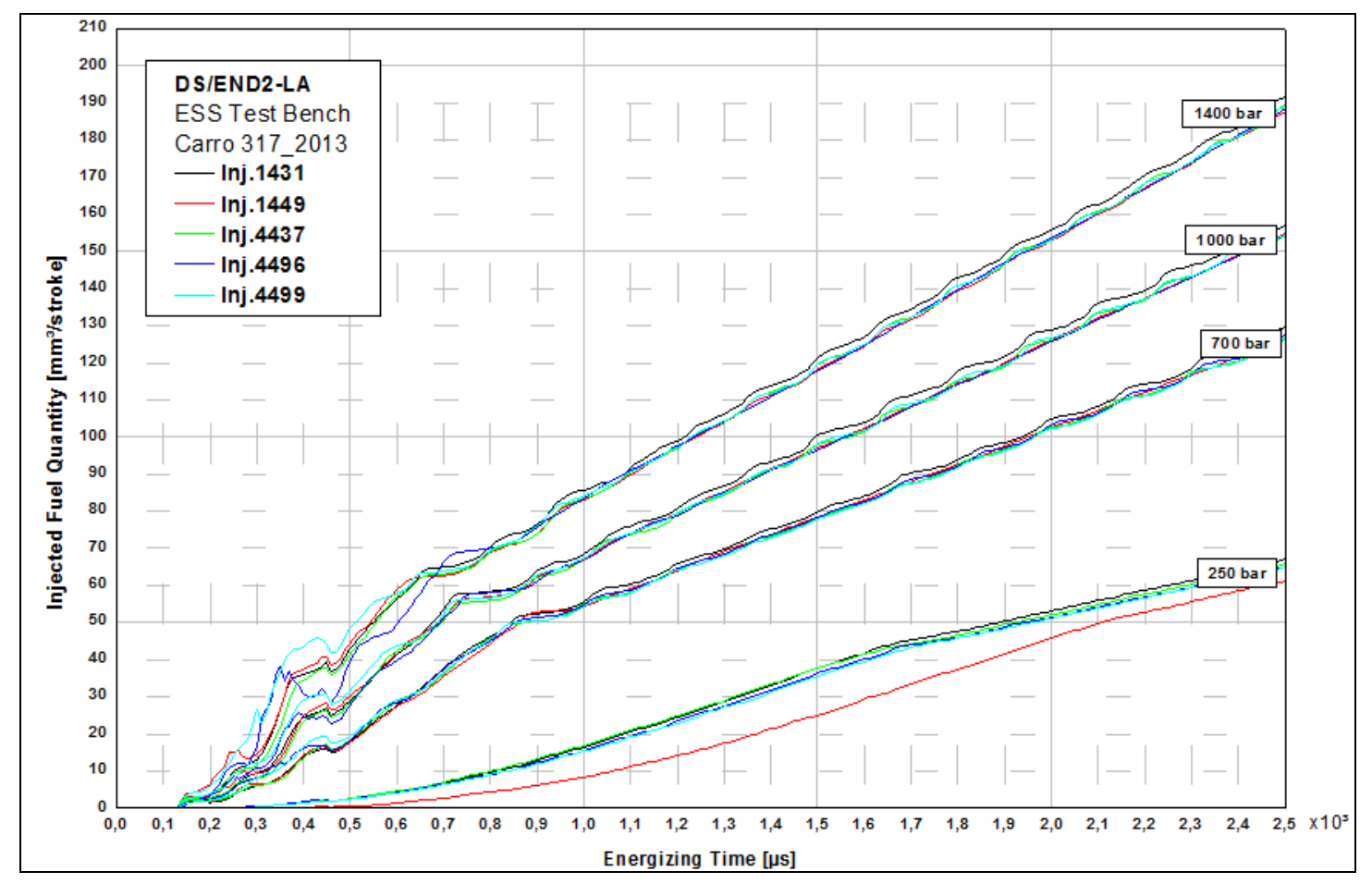

Figura 3: Débito dos injetores após os testes- veículo 317

As análises do rail de cada um dos veículos se demonstraram conforme o esperado, sem deteriorações fora do normal. Diante do exposto ficou constatado que o uso do AMD 10 nesta configuração de motor não comprometeu a vida útil do sistema de injeção de combustível. Todavia, não existem dados estatísticos suficientes que possam ratificar estes resultados obtidos.

\subsection{Filtro de Combustível}

No ônibus 318 e 317, tanto o pré-filtro quanto o filtro de combustível, utilizados foram fornecidos pela Parker Hannifin. Já no veículo 316, o pré-filtro é da Parker Hannifin enquanto o filtro de combustível é da Cummins Filtration. Todos os filtros foram substituídos no período programado de revisão e foram submetidos a análises em bancada.

\subsubsection{Parker Hannifin}

O procedimento de restrição ao fluxo utilizado pela Parker Hannifin para avaliar o funcionamento dos filtros consiste em regular a vazão inicial de teste com 30 GPH, aumentar gradativamente de $10 \mathrm{em} 10 \mathrm{GPH}$, até a vazão nominal de cada filtro atinja $120 \mathrm{GPH}$, para então realizar a leitura de variação de pressão a cada regulagem de vazão. Uma leitura superior aos $380 \mathrm{mmHg}(0,5$ bar $)$ indica saturação do filtro. A figura 4 apresenta um resumo dos resultados. 


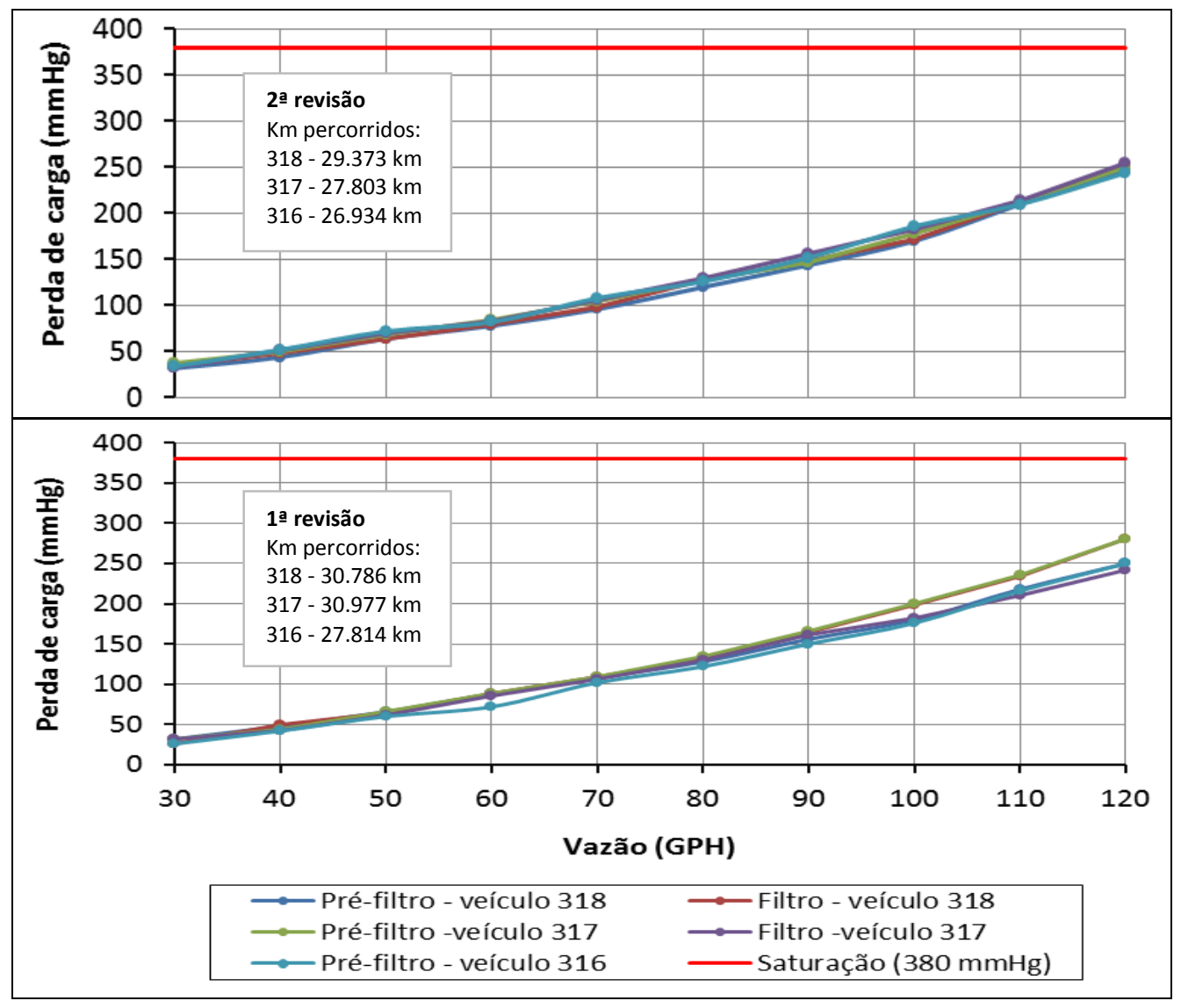

Figura 4: Curvas das restrições conforme SAE J905 [4]

Todas as características dos elementos filtrantes estavam inalteradas, aspectos visuais e estruturais. Apresentaram restrição abaixo do recomendado para troca por saturação.

\subsubsection{Cummins Filtration}

O procedimento utilizado pela Cummins Filtration realiza uma leitura contínua dos valores de restrição para um fluxo contínuo de 0 a 20 litros por minuto. Os valores de restrição não podem ser superiores a $30 \mathrm{kPa}$, caso contrário o mesmo indicará a saturação do filtro.

Tanto o filtro de combustível retirado durante a $1^{\mathrm{a}}$ revisão quanto na $2^{\mathrm{a}}$ revisão não apresentaram problemas, conforme o mostrado na figura 5, atendendo desta forma, as solicitações da aplicação a que foram submetidos. 


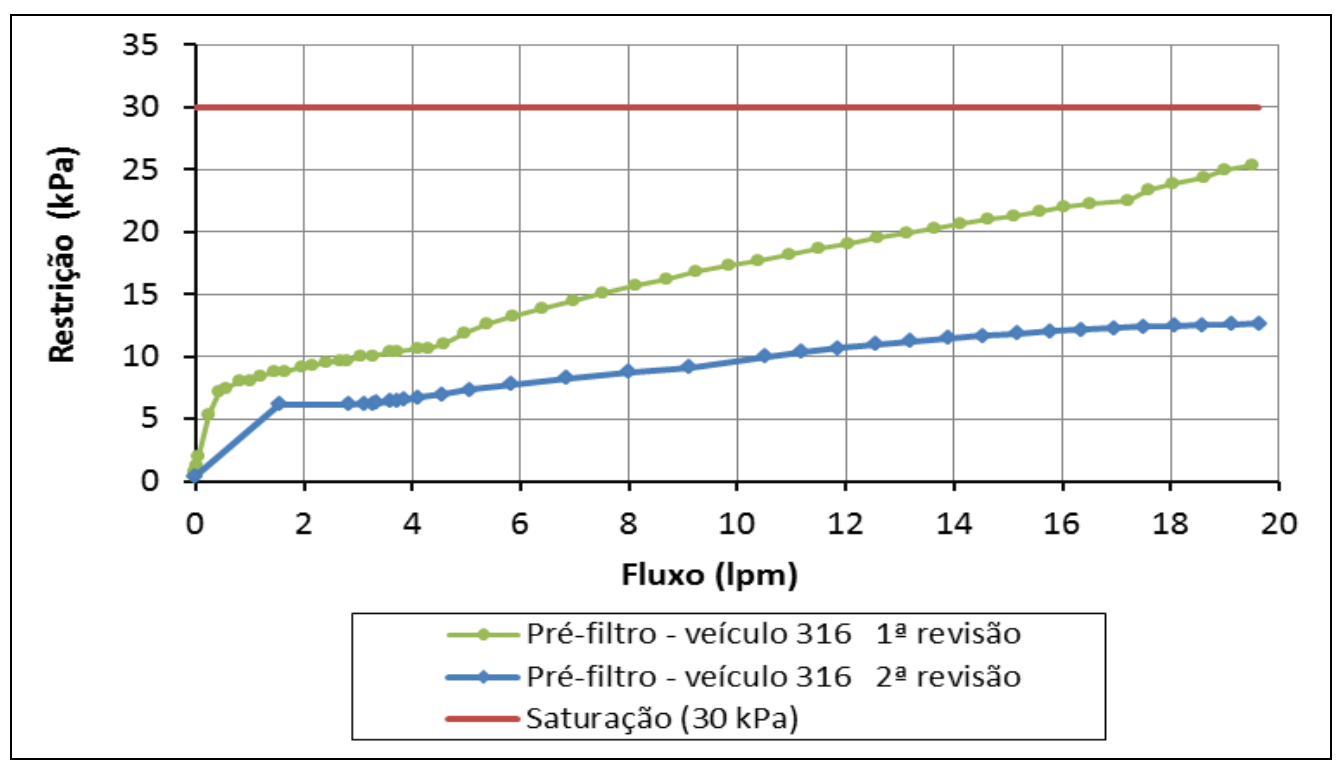

Figura 5: Curvas das restrições conforme SAE J905

\subsection{Tanque de Combustível}

A Unipac realizou testes de performance nos tanques de combustível a fim de identificar qualquer problema devido a utilização do AMD 10. A tabela 4 mostra os diferentes testes aplicados em cada tanque.

Tabela 4: Testes mecânicos conforme norma VW TL 668 [5]

\begin{tabular}{|l|l|}
\hline Veículos & Testes Aplicados \\
\hline 318 & Corte da amostra - Verificação interna \\
\hline 317 & Resistência mecânica \\
\hline 316 & Comportamento sob solicitação de impacto \\
\hline
\end{tabular}

\subsubsection{Corte da Amostra - Verificação Interna}

O teste consistiu em cortar a amostra para realização de análise visual da parte interna do tanque. A figura 6 apresenta o tanque de combustível do veículo 318 . Pôde-se constatar inexistência de qualquer alteração em suas dimensões originais. Também não foi detectada nenhuma irregularidade no material. 

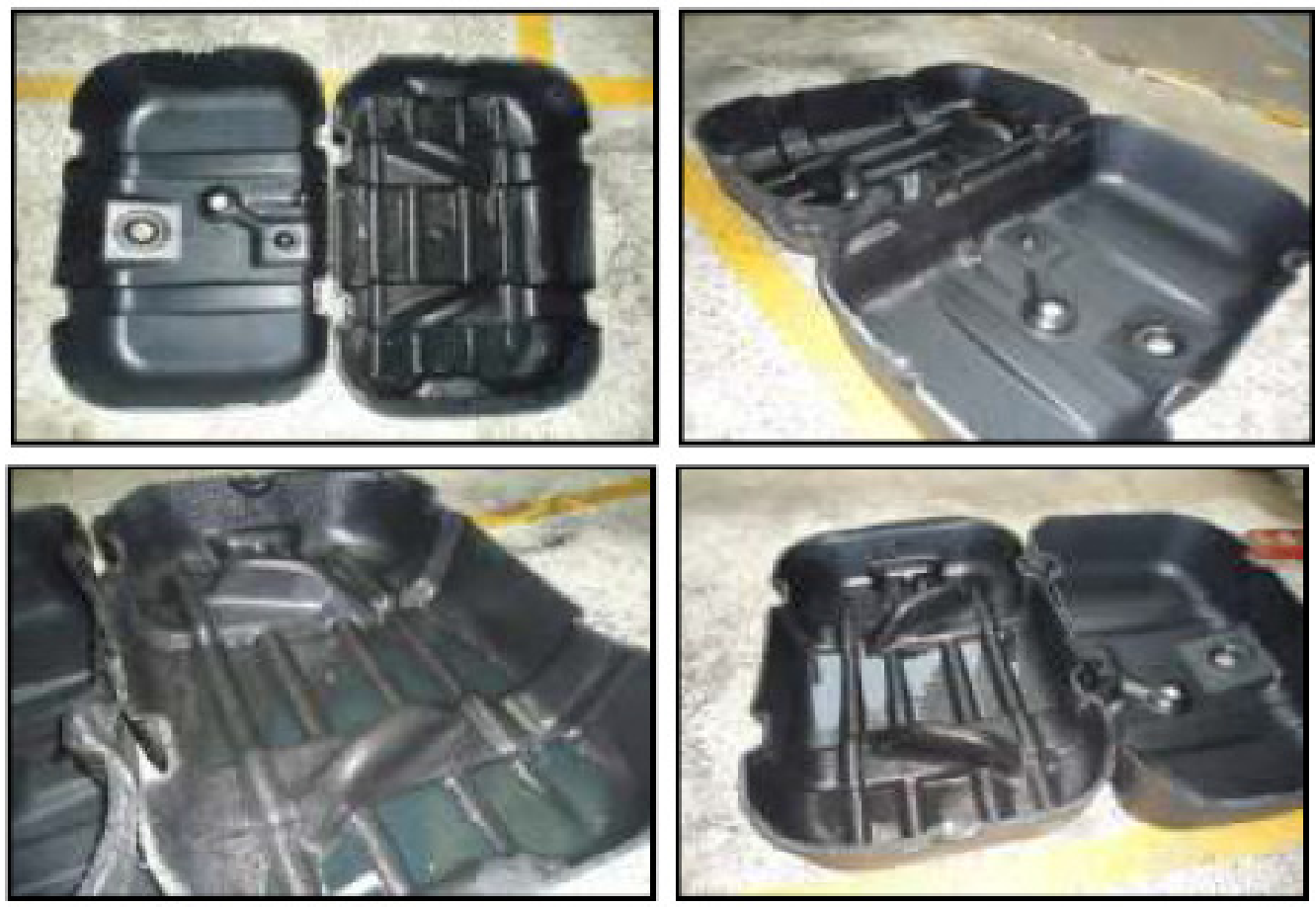

Figura 6: Tanque de combustível cortado do veículo 318

\subsubsection{Resistência Mecânica}

Neste caso o reservatório foi abastecido totalmente com água, e colocado numa estufa por 5 horas, a uma temperatura de $53 \pm 2^{\circ} \mathrm{C}$ e submetido a uma pressão relativa interna de 0,3 bar. No final do teste o tanque não apresentou vazamentos ou trincas seguindo as exigências do teste.

\subsubsection{Comportamento Sob Solicitação de Impacto}

O reservatório foi enchido totalmente com água e monoetilenoglicol a uma temperatura de $-35 \pm 2^{\circ} \mathrm{C}$. As características deste fluido possibilitam que ele permaneça no estado líquido. Posteriormente o tanque é montado num banco de provas e é simulado um impacto frontal. A energia no mento do impacto deverá ser de pelo menos 4.000J. A figura 7 apresenta este ensaio. 

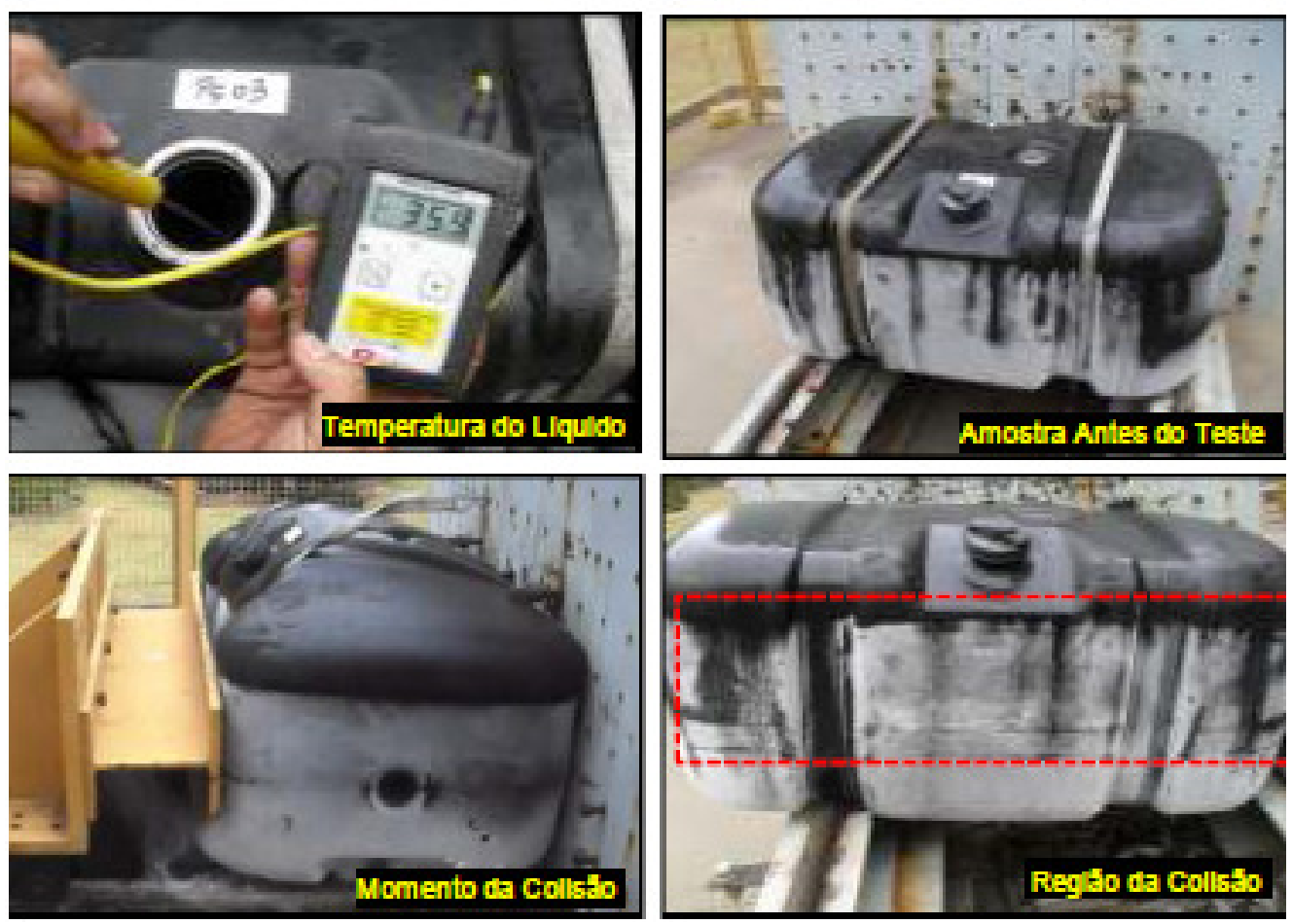

Figura 7: Teste sob solicitação de impacto do veículo 316

Após o teste foi verificado que o reservatório não apresentou trincas nem vazamento conforme o exigido pela norma VW TL 668.

\subsection{Tubulação de Combustível}

Após o teste, foram retiradas as tubulações de combustível dos três veículos e enviadas para seu respectivo fornecedor, a VOSS Automotive, donde foi feito uma avaliação das propriedades mecânicas de cada componente.

Os ônibus rodaram com duas tubulações diferentes: 318 e 317 com tubulação multicamada PA12 + PVDF; e o 316 com tubulação PA12, que historicamente é a mais utilizada. As conexões utilizadas nas tubulações são iguais as de em série, da família SV246.

Foram selecionados três tipos de testes mecânicos com maior influência nas tubulações: alongamento a ruptura, pressão de estouro e teste de impacto $\left(23^{\circ} \mathrm{C}\right.$ e $\left.-40^{\circ} \mathrm{C}\right)$. Nas tabelas 5 e 6 são apresentados os resultados de três amostras dos veículos 318 e 317 após uma rodagem de $85.988 \mathrm{~km}$ e $89.801 \mathrm{~km}$, respectivamente.

Tabela 5: Testes mecânicos conforme norma DIN 73.378 [6] 


\begin{tabular}{|c|c|c|}
\hline \multicolumn{3}{|c|}{ Veículo 318 - Tubulação multicamada PA12 + PVDF } \\
\hline Ensaio & Especificação & Resultados ( 3 amostras) \\
\hline Pressão de estouro $\left(\mathrm{N} / \mathrm{mm}^{2}\right)$ & Min. 27 & $35,27-33,35-34,88$ \\
\hline Resistência ao impacto $23{ }^{\circ} \mathrm{C}(\mathrm{J})$ & Sem fratura & Sem fratura \\
\hline Elasticidade $\left(\mathrm{N} / \mathrm{mm}^{2}\right)$ & $>350$ & $542-479-480$ \\
\hline Alongamento (\%) & Min. 100 & $152-135-216$ \\
\hline \multicolumn{3}{|c|}{ Veículo 317 - Tubulação multicamada PA12 + PVDF } \\
\hline Ensaio & Especificação & Resultados (3 amostras) \\
\hline Pressão de estouro $\left(\mathrm{N} / \mathrm{mm}^{2}\right)$ & Min. 27 & $33,35-34,50-35,27$ \\
\hline Resistência ao impacto $23{ }^{\circ} \mathrm{C}(\mathrm{J})$ & Sem fratura & Sem fratura \\
\hline Elasticidade $\left(\mathrm{N} / \mathrm{mm}^{2}\right)$ & $>350$ & $509-484-487$ \\
\hline Alongamento $(\%)$ & Min. 100 & $237-248-244$ \\
\hline
\end{tabular}

Os resultados dos testes mecânicos das tubulações utilizadas no veículo 316 são apresentados na tabela 6, após uma rodagem de $84.301 \mathrm{~km}$.

Tabela 6: Testes mecânicos conforme norma DIN 73.378

\begin{tabular}{|l|c|c|}
\hline \multicolumn{3}{|c|}{ Veículo 318 - tubulação PA12 } \\
\hline Ensaio & Especificação & Resultados (3 amostras) \\
\hline Pressão de estouro $\left(\mathrm{N} / \mathrm{mm}^{2}\right)$ & Min. 27 & $27,96-27,60-27,98$ \\
\hline Resistência ao impacto $23{ }^{\circ} \mathrm{C}(\mathrm{J})$ & Sem fratura & Sem fratura \\
\hline Elasticidade $\left(\mathrm{N} / \mathrm{mm}^{2}\right)$ & $>350$ & $413-380-397$ \\
\hline Alongamento $(\%)$ & Min. 100 & $254-262-276$ \\
\hline
\end{tabular}

Excluindo-se a interferência da má inserção dos conectores na tubulação e as fraturas observadas no teste de resistência ao impacto a $-40^{\circ} \mathrm{C}$, onde as três amostras falharam, os resultados demostraram que os dois materiais analisados tiveram resultados satisfatórios. Entretanto, cabe-se ressaltar que estes desvios não se configuram como impeditivos, estando assim os dois materiais aptos para a utilização de AMD 10. Também não foi identificada nenhuma avaria externa nas tubulações.

\subsection{Desempenho Operacional}

\subsubsection{Consumo de Combustível}


A figura 8 mostra o consumo de combustível dos veículos que rodaram com AMD 10 durante o ano de teste. Pode-se observar que o consumo dos ônibus que operaram com AMD 10 não apresentaram variações com relação à media do consumo da frota com óleo diesel S50/B5.

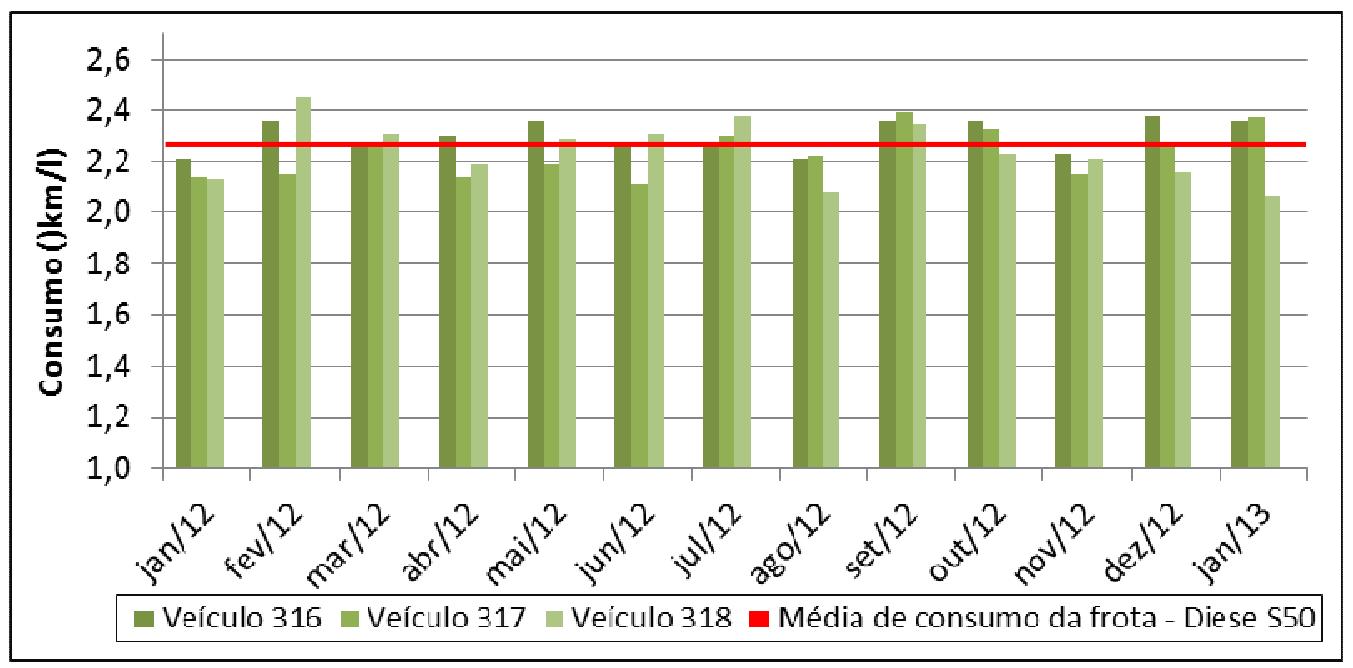

Figura 8: Análise do consumo de combustível [7]

Os dados de consumo de combustível foram extraídos das planilhas de controle operacional da Viação Santa Brígida. Os veículos 316, 317 e 318 tiveram um consumo médio de $2,30 \mathrm{~km} / 1,2,22 \mathrm{~km} / 1$ e $2,25 \mathrm{~km} / 1$, respectivamente, enquanto o consumo medio da frota movida a óleo diesel S50/B5 foi de 2,23 km/1.

\subsubsection{Ocorrência de Falhas}

Com base nas análises das planilhas de controle operacional da Viação Santa Brígida, não foram relatadas ocorrências em nenhum dos veículos testados que pudessem ser associadas ao uso de AMD 10.

\section{CONCLUSÃO}

A mistura AMD 10 atende às especificações estabelecidas pela Resolução ANP n 42/2009, que define as propriedades físico-químicas do óleo diesel S50/B5. Desta forma, a adição deste percentual de diesel de cana ainda mantém o óleo diesel S50/B5 em conformidade com o comercializado no Brasil.

Nos três ônibus que operaram com AMD 10 não foi observado nenhuma alteração com relação às peças que compõem o sistema de combustível, componentes do motor e sistema de injeção. Não houve alteração no período de troca de filtros de combustível devido a sua saturação prematura. 
Somente o injetor 1449 do ônibus 317 mostrou curva de débito injetado abaixo do estado de fornecimento, porém sem influência funcional sobre o motor. Isto se deve provavelmente a leve formação de depósitos. Todavia, devido à inexistência de dados estatísticos suficientes, não é possível correlacionar, ou ratificar, estes resultados obtidos com a utilização de AMD 10.

Os ônibus 316 e 318 apresentaram um aumento no consumo de combustível de 3,13\% e 0,89\%, respectivamente, quando comparados a média da frota movida a óleo diesel S50/B5. Para o ônibus 317 houve uma redução de $0,44 \%$ do consumo médio de combustível, em relação a média dos veículos movidos a óleo diesel S50/B5.

\section{REFERÊNCIAS}

[1] WUlfHROST, G.; PRIESTER, R.; MIRAMONTES, M.. What Cities Want: How Cities Plan Future Mobility. MAN SE \& Technische Universität München, Germany, 2013.

[2] A Lei $\mathbf{n}^{\circ}$ 14.933/09 e seus Impactos no Transporte Público; Apresentação SPTrans; Superintendência de Serviços Veiculares, São Paulo, 2010.

[3] CHAVES, R.O.; MARQUES, G.G.; IZQUIERDO, L.S.; SANAIOTTI, G.N.. A Comprehensive Evaluation of Performance and Emissions from Sugarcane Diesel in Medium Duty Engines. SAE International Technical Paper, 2013. Ainda a ser publicado.

[4] SAE J905:2009 - "Fuel Filter Test Methods". The purpose of this fuel filter test method is to provide standardized methods for evaluating the performance characteristics of fuel filters by bench test methods.

[5] VW TL 668:2009 - "Fuel Tank: Strength Requirements". This standard defines requirements for all gasoline and diesel fuel tanks installed in vehicles (including fuel filler neck and all add-on parts) as well as separately installed fuel expansion tanks independently of the material used.

[6] DIN 73.378:1996 - "Polyamide tubing for use in motor vehicles". For polyamide tubings, the material, the dimensions, the requirements, the test procedures and the marking are stated."

[7] Planilha de controle operacional da Viação Santa Brígida. Jan a Dez/2012.

\section{CONTATO DO AUTOR}

Lian S. Izquierdo pode ser contactado através do seguinte e-mail:

lian.izquierdo@volkswagen.com.br 
Anexo A: Imagens do interior da câmara de combustão captadas durante a boroscopia Veículo 318 (antes dos testes)
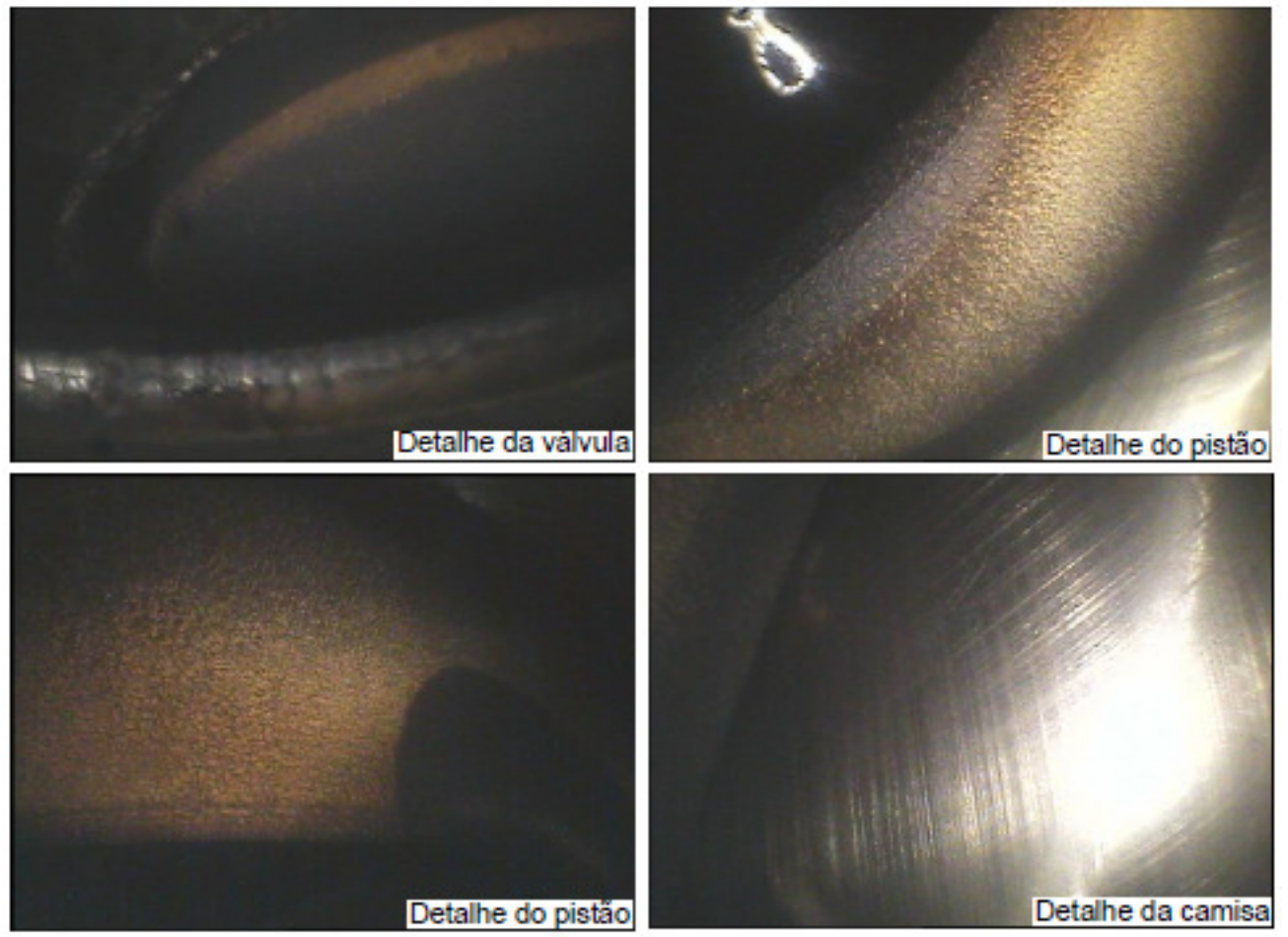

Veículo 318 (depois dos testes)
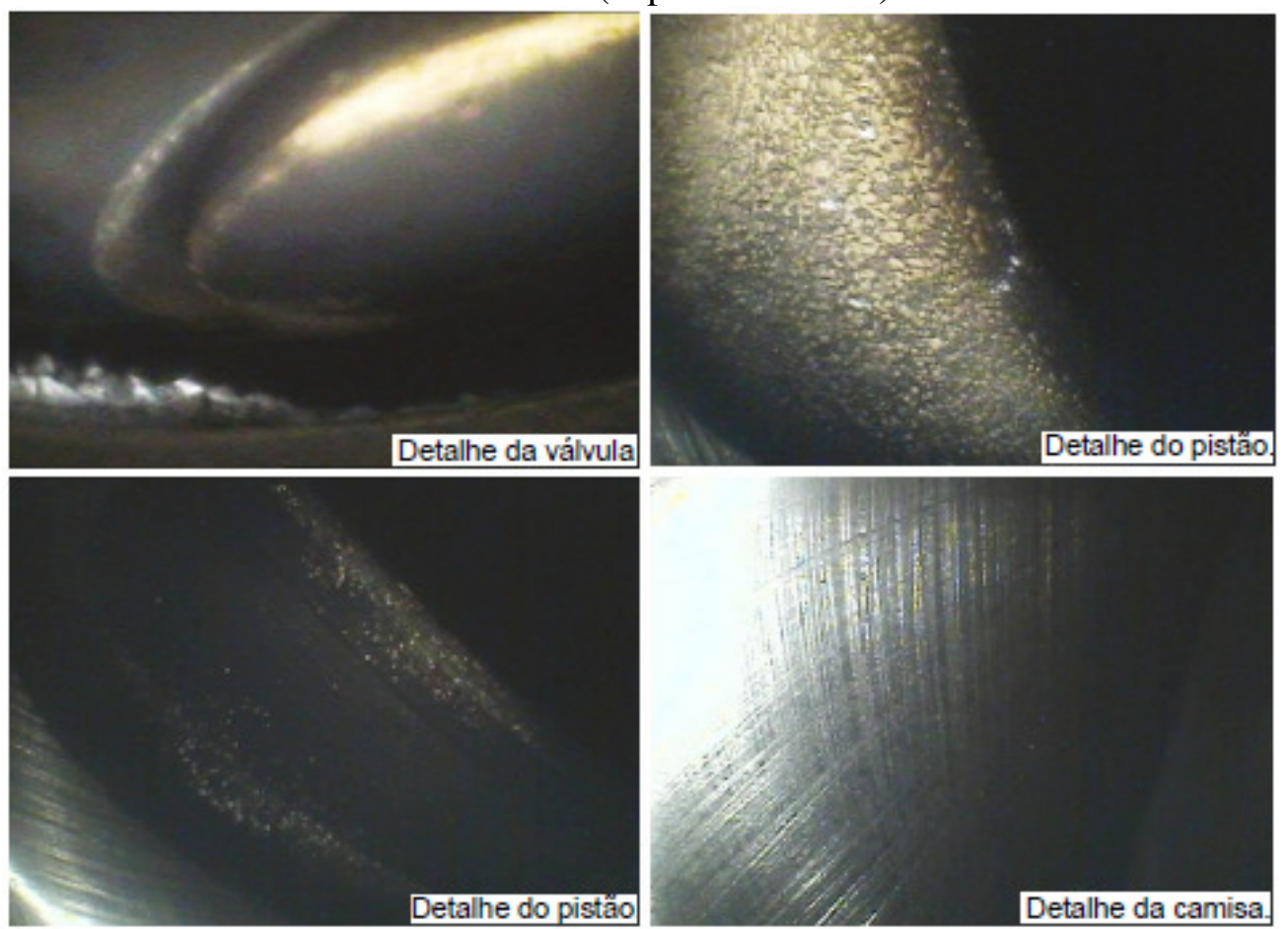

Page 15 of 16 
Anexo B: Imagens do interior da câmara de combustão captadas durante a boroscopia

Veículo 317 (antes dos testes)

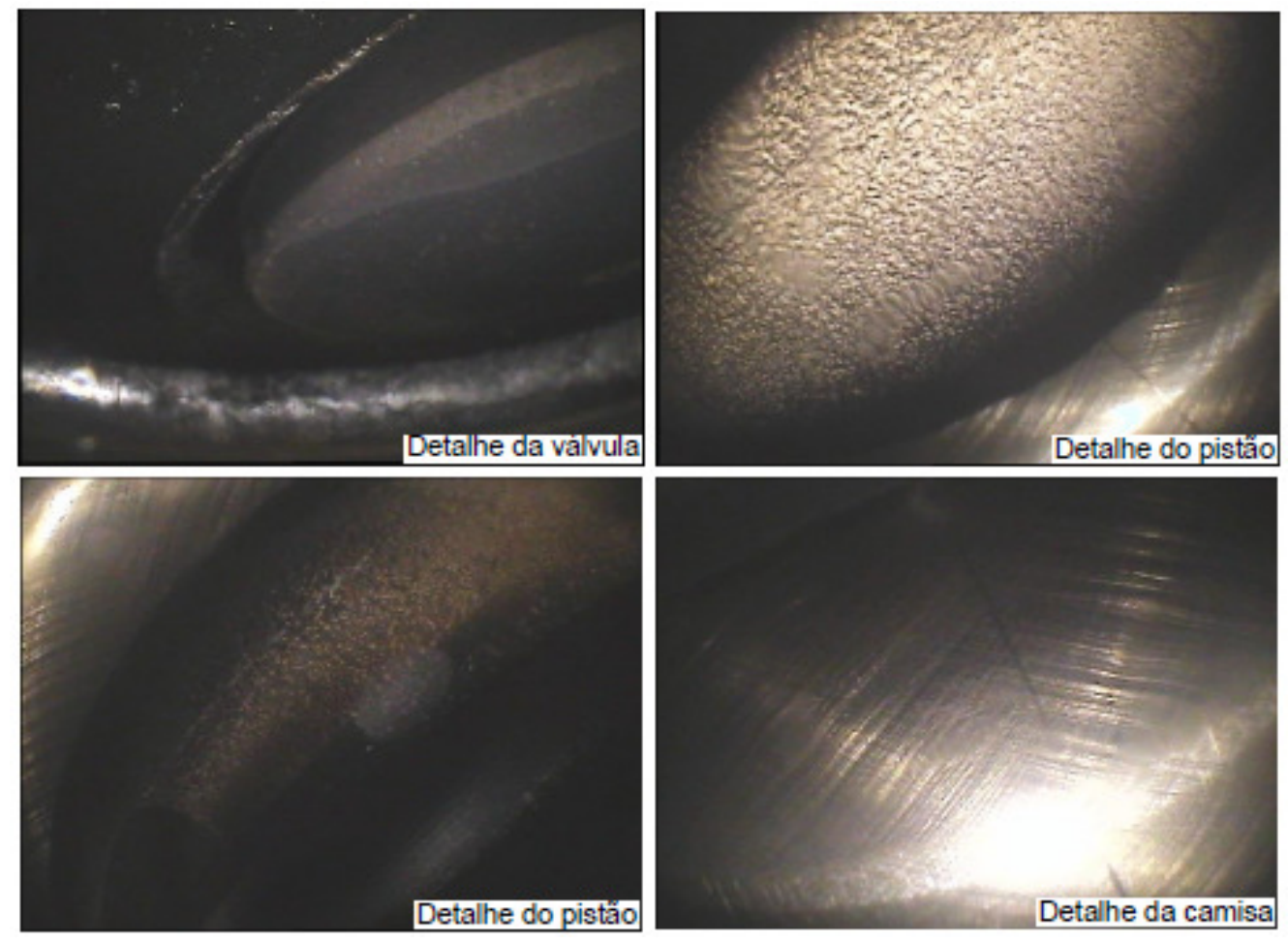

Veículo 317 (depois dos testes)
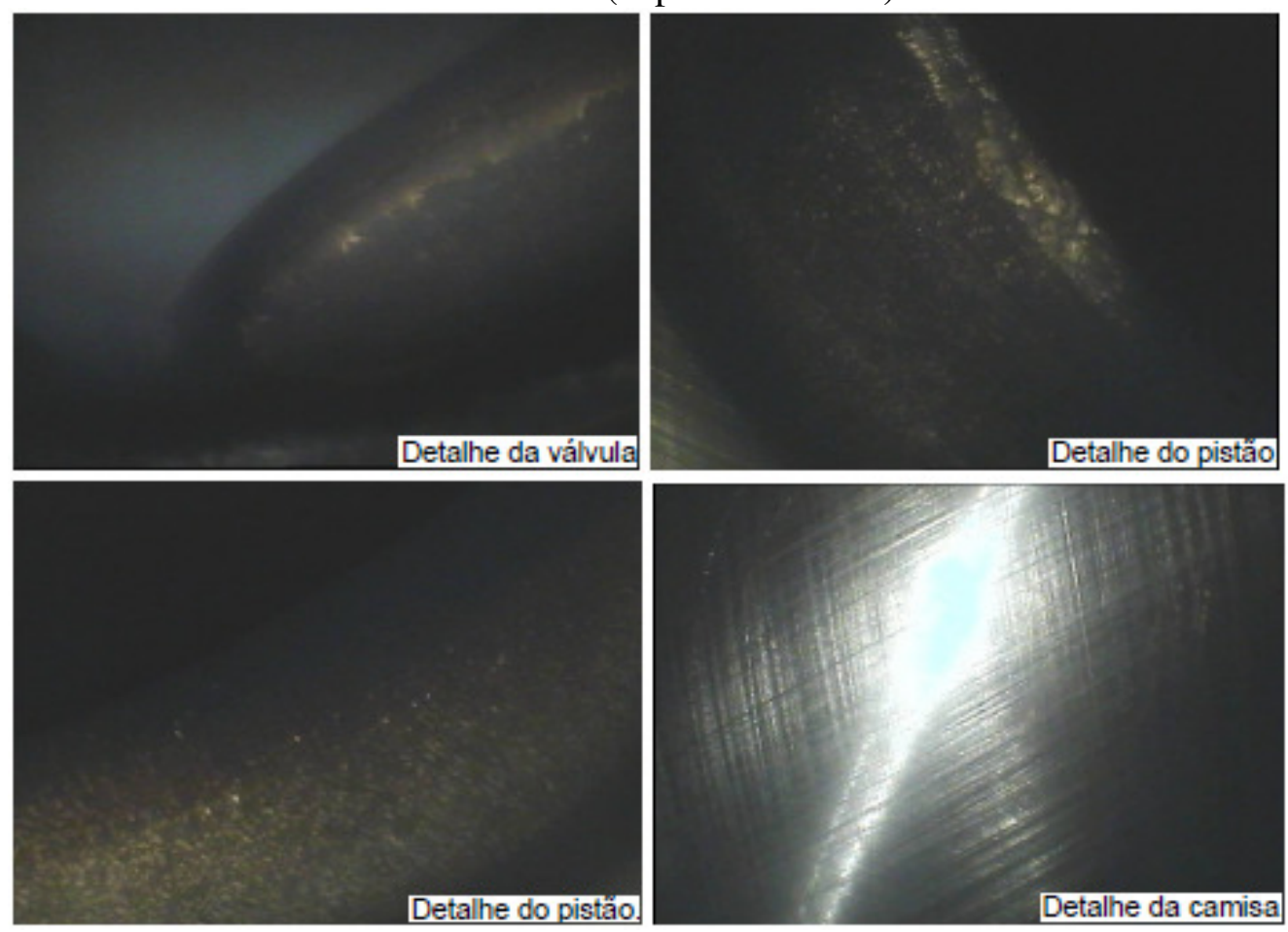

Page 16 of 16 